\title{
Space for Hygiene in Housing Architecture
}

\author{
Claus Bech-Danielsen \\ Center of Housing Research, Aalborg University, Copenhagen 2450, Denmark
}

\begin{abstract}
In this paper, the author focuses on spaces used for personal hygiene - the bathroom. The paper begins with a description of the hygienic movement in the late 19th century. At that time, urinating took place in semi-public spaces outside the dwelling. Today, the WC has moved well into the dwelling, and in many dwellings, the bathroom has developed as the most private space. Thus, the bathroom can be regarded as the last domain of privacy in today's housing, and in a number of new dwellings this quality is exploited in new ways. The development of "space for hygiene" in the 20th century will be studied by analyzing the spatial organization of dwellings.
\end{abstract}

Key words: Hygiene, health, bathroom, housing architecture, modern housing, everyday life.

\section{Introduction}

This paper is part of a research project that surveys a series of momentous changes in residential architecture, which have occurred over the last 100 years. This was done by focusing on a number of specific functions of the dwelling: cooking, bathing, playing, storing etc.. In a previous issue of this journal [1], the author has described the development of the kitchen in housing architecture in the 20th century. In this paper, the focus is on the hygienic function of the bathroom.

In former research projects, the author has described how hygienic concerns have been an important driving force in the development of modern architecture and urban planning [2]. In this paper, the author focuses on the spaces in the dwelling that frames the personal hygiene. Thereby, the paper highlights an area of housing architecture that has been analyzed very inadequately. The literature on housing architecture often ignores the bathroom - in descriptions as well as visual representations, and it appears that the space for toilet functions has been taboo and not a space that has received a great deal of attention.

This is remarkable in light of the importance that

Corresponding author: Claus Bech-Danielsen, professor, research field: architecture.E-mail: cbd@sbi.aau.dk. the hygienic movement has had on modern architecture and on planning in general. Thus, the bathroom has led a hidden life. Yet, the bathroom has undergone drastic changes over the last 100 years. As will be seen, it is only at the beginning of 20th century that bathrooms appear in dwellings, and also the idea of being able to go to the toilet inside your home is developed at the same time. These functions used to take place in public baths and semi-public courtyard areas. Today the same functions take place in bathrooms, which are considered the most private space of the dwelling.

The paper describes the development of layout and design of the bathrooms by focusing on five periods: "Hundred years ago", "1920s and 1930s", "1940s and 1950s", "1960s and 1970s", "1980s and 1990s" and "Today". For each of these periods, the author describes the international development that Danish housing architecture and bathroom design have been inspired by. On this background, the author describes the Danish development-how the international trends affected the work of Danish architects and how the same trends affected the more anonymous housing in Denmark, such as industrial housing.

The method mainly consists of typological studies. Thus, the author has analyzed examples of housing regarded as typical of their periods. Primarily these 
analyses focused on plans of dwellings, studying the size, the location and the design of bathrooms. The emergence of conditions typical of each individual period was often discovered through comparisons across the different periods. The method also included literature studies. These studies have focused on the one hand on societal and cultural trends (health, hygiene, rationality, food culture, gender, sustainability, consumerism etc.) and on the other hand on housing architecture, changing residential conditions as well as bathroom design.

In this paper, the author presents the preliminary results of the study. It will be shown how bathroom design and its relation to everyday life in the dwelling has changed over time. With focus on the bathroom, it is shown that housing architecture has undergone drastic changes over the last hundred years. Thus it becomes obvious that the concept of "good housing" has constantly been changing. We may imagine that housing today will meet future housing needs, but in the light of the previous changes we have to realize that the future is likely to bring great changes.

\section{A Hundred Years Ago: Closet Rooms and Bathrooms}

2.1 Cities in the Age of Industrialisation and the Hygienic Movement

Industrialisation in $1800 \mathrm{~s}$ led to a massive urbanization, and living conditions in the rapidly growing industrial cities became critical. Rats were everywhere in the streets running around between waste and horse droppings, in the courtyards water from the kitchen drains mixed with leakage from latrines, and the dwellings were cold and humid. Life in the cities was unhealthy, bacteria had good growing conditions and epidemic diseases were rampant. In $1853,5,000$ people (representing 4\% of Copenhagen's population) died of a cholera epidemic [2]. This gave impetus to the hygienic movement, which identified development of sewage systems as the main way of fighting the dangerous health conditions in the cities.
At the time, waste from latrines was removed by waste collectors. They transported the waste out of the city twice a week [3], but the renovation was inadequate and leakage from latrines gave off an indescribable stench in the city [4]. In Copenhagen, construction of sewers started in 1860 , but the plans were met with resistance from peasants who used the waste from latrines for manure. However, the health policy interests prevailed, and in 1897, a plan for a sewerage system for the whole city was adopted. Thus, the idea of having bathrooms and water closets inside the dwelling could be realized.

However, contemporary baths and toilet facilities were still very different from what we know today. Today we may have a well established idea that any accommodation will include a bathroom, and we also have the idea that the bathroom as a minimum should include a sink, WC and a shower. It was not always like that. For instance, in the early 20th century, it was inconceivable that the bath and lavatory should be located in the same room.

\subsection{Closet Rooms a Hundred Years Ago}

The water closet was invented in England in the late 1500s [5], but it was not until the late 1800s that it was put into production for real, and in the early 20th century still only a few homes were equipped with a water closet. In urban areas, most residents relieved themselves in latrines in the courtyards, but some of the larger apartments had a lavatory (without drainage). In these apartments, the bucket in the lavatory was emptied by servants, and even though they emptied the bucket regularly, a stench spread from it.

This was one of the reasons why the lavatory was located far from the representative part of the apartment (Fig. 1). Another reason why the lavatory was hidden away is found in a moral code that was developed by the contemporary bourgeoisie $[5,6]$. The code dictated that toileting should not be mentioned in public-toileting should take place 
discreetly behind closed doors and should not be seen or smelled. What had once been an activity as free of shame as brushing your hair became associated with feelings of embarrassment and disgust, writes Hudson [5]. What had once occurred in public spaces (in the courtyard latrines in cities and in cowsheds or manure pits in the country) became taboo and was concealed, and the resulting waste should flow into the sewer as discreetly and hygienically as possible.

This was expressed in architecture. In the detached houses of the bourgeoisie, the lavatory was typically located in a room in the basement (Fig. 2), while the water closet in the more affluent villas was usually placed in a small room on the upper floor next to the bedrooms. In both cases, the toilet function was far removed from the representative rooms, and not easily accessible to guests. This was also the case in many contemporary noble apartments. The lavatory/WC was typically located at the end of a corridor, in a space the size of a closet without windows to the outside and thus without daylight and without the possibility of ventilation. There was rarely electric lighting in contemporary homes, and the small room

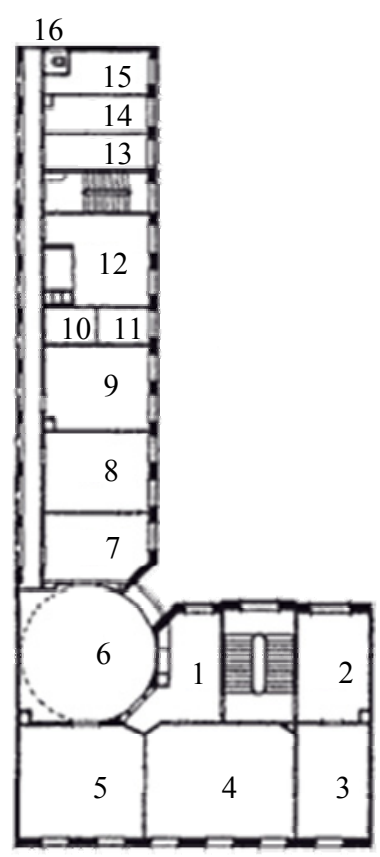

Fig. 1 Danish apartment from 1903, lavatory (16) is at the end of a long corridor in the remotest corner of the apartment.
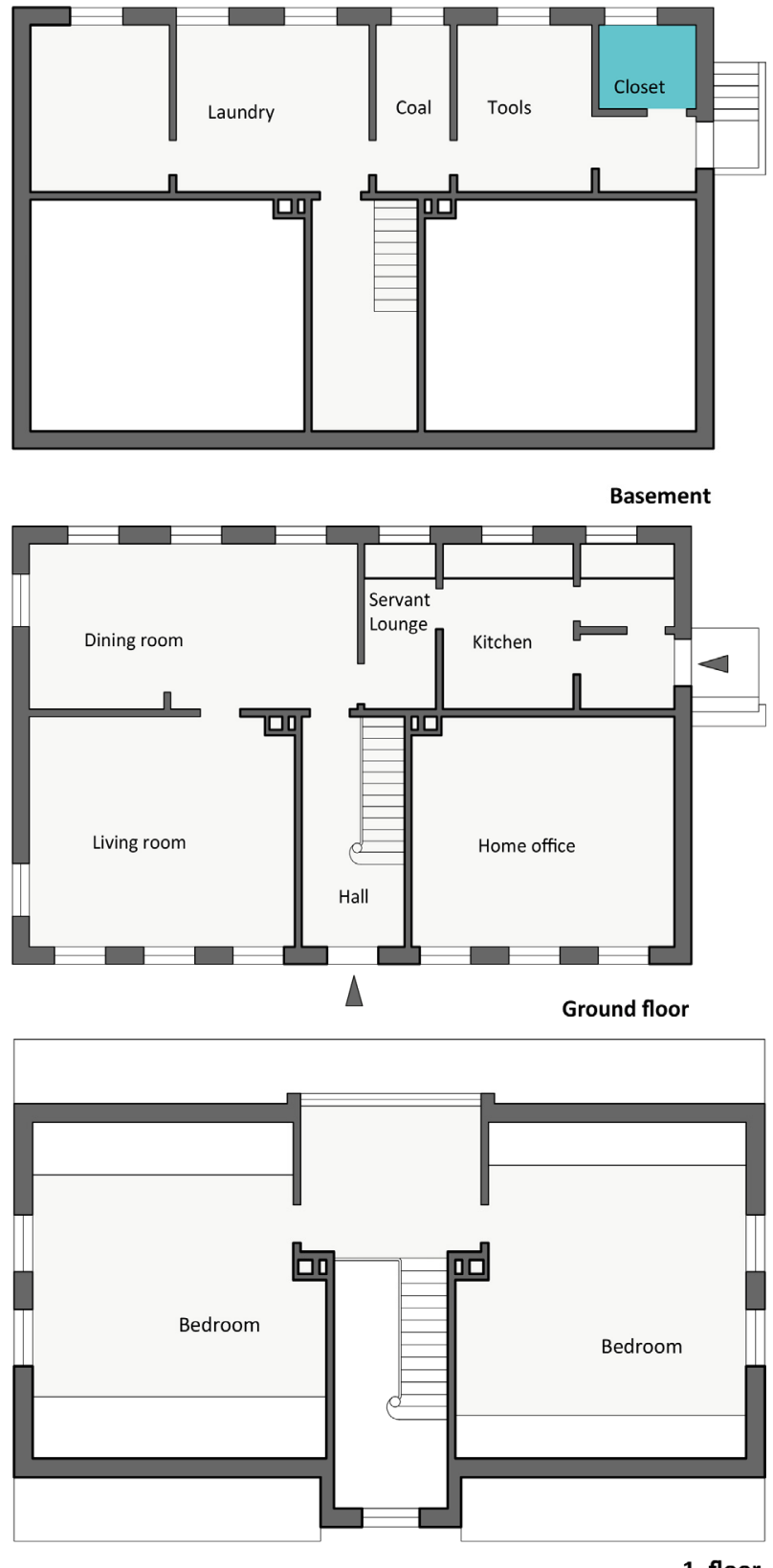

Fig. 2 Danish house from 1915, lavatory is placed in a distant corner of the basement.

was dark and cramped. Toileting at this time was to overcome, as evidenced by the epithet that the lavatory had in English-speaking countries: "The necessary" [7].

However, it soon became popular to have a WC in the dwelling, and in the early 20th century, it became an important competitive factor in the housing market.

A frequent cause of contemporary movements was a desire to replace latrines in the courtyard by a WC in 
the apartment [3].

\subsection{Bathrooms a Hundred Years Ago}

It was not until the mid-19th century that the wealthiest part of the population started to have running water installed in homes. Before that time, all water was retrieved by hand from a well [8] and when running water was installed, it was cold and had to be heated on the kitchen stove.

In 1906 , only $3.8 \%$ of the Copenhagen dwellings were equipped with a bathroom [3]. In most homes, personal hygiene took place somewhere else-in bourgeois homes typically in the bedroom [3]. In many families, the bedrooms underwent a dramatic transformation in those years: Four-poster beds, heavy curtains and dark wallpaper were replaced, and the room was designed light and airy, with a dressing table and a washstand [3]. Personal care took place here in the morning, when the maid had brought hot water, which she removed again after use. The weekly bath took place on Saturdays, when the children were bathed in a zinc tub in the kitchen or dining room and the adults went to the public bath [3].

Thus, the standard of the bourgeoisie was a daily wash and a weekly bath. The working class obtained a similar standard of hygiene, but as their housing was considerably smaller and rarely contained a bedroom, they washed in the kitchen or in the living room in the wintertime when the kitchen was too cold. The weekly bath was only for the better off of the working class, as the zinc tub was rented and the hot water purchased for the occasion

It was obviously the most wealthy citizens who first equipped their dwelling with a proper bathroom. In existing houses spaces that originally had a different purpose was rebuilt into bathrooms. Materials such as wooden floors, stained glass, stucco and wood carvings were usually left in place and often the room was decorated with paintings on the walls and furnished with bookshelves, sofas and armchairs [9]. It was therefore not like "wet room", as we understand it today.
Dwellings in new construction often had a bathroom, and also these bathrooms were designed and furnished in a way that was reminiscent of a living room. For example, washbasins and bathtubs were often hidden in cupboards and chests of drawers [9]. Thus, as will be shown at the end of this paper, contemporary bathrooms had features in common with today's bathroom trends where ordinary furnishings and workspace become part of the bathroom.

Fairly early in the 20th century, the bathrooms started to look more like what we know today. They had tiled floors, and pipes were exposed, so they could easily be inspected and cleaned. The bathrooms were optimized and designed as a functional space, with practical materials that could withstand water and could easily be wiped off. Bathtubs (mounted on feet that made it easy to clean beneath them) became quite common, while showers were still rare and were only found in particularly posh homes [9]. Bathroom equipment was increasingly transformed from single furniture to be contiguous parts of the architectural space [10].

Among contemporary architects, especially one should be mentioned when speaking of hygiene and bathrooms. The Austrian architect Adolf Loos (1870-1933) placed great emphasis on personal hygiene, and he considered it important that the architects focused on bathroom design. According to Loos, the bathroom was not only an extremely important element of the modern apartment, but also a tool for measuring the degree of the cultural development of a population [11]. In a remarkable contrast to the last decade's attempts to reduce water consumption in homes, he sees it as an urgent tasks to increase the amount of water spent in the bathroom [11].

But even the homes designed by Loos were not always equipped with a bathroom and running water. This shows how novel the whole idea of having a bathroom as an integral part of the dwelling was at the time. Even a very spacious dwelling like "Stoesel 
House" (1911-1913) is not equipped with a bathroom. In other villas by Adolf Loos, the clients were however more receptive to his ideas. For example, the children's room and the parents' bedroom in "Horner House" from 1912 both have direct access to a shared bathroom. The bathroom contains a WC in a separate room. It must have been a novel concept at the time to combine the bath and the WC, which were usually found in separate rooms.

\section{1920s and 1930s: The Modernistic Period}

\subsection{Bathrooms and WC Rooms in Early Modernism}

The hygienic ideals had great significance when the modernistic architecture and planning concept was developed in the 1920s and 1930s. This was the case at city level, as expressed in the Athens Charter of 1933, which aimed to improve the health conditions in urban areas by ensuring access to light and air and by separating housing from polluting industries and traffic. As will be shown similar considerations affected the design of modernistic housing.

Adolf Loos was among the leading architects in the development of clinically clean housing. This was for example expressed in Moller Villa, designed by Loos in 1926-1927. The dwelling has a bathroom with both shower and tub and a WC in a small separate room [11]. The bathroom is located on the second floor near the bedrooms, but also on the third floor (which contains a roof terrace, a guest room and a studio) and in the basement (which contains rooms for housekeeper and maid, laundry, garage and storage) there are small WC rooms. Thus, the house contains three WCs, but none of they are located on the primary floor, first room with a hall, library, living room, kitchen and exit to the terrace.

From today's point of view the WCs in Moller Villa is not suitably located, for instance in relation to guests. However, Moller Villa is designed according to the contemporary moral code (described above), which demanded that toileting should take place in secret. This code was still valid in the 1920s and 1930, and therefore the WC was placed far from the company in the living room.

As is the case in the Moller Villa, the WC was located in small separate spaces in the majority of the houses of the period. However, there are several examples of a separate WC room being accessed from the bathroom, and thus the linkage between bath and WC is introduced. In other dwellings, the WC sneaks into the very bathroom, often located a bit away from the other functions of the bathroom. We find an early example of this in the villas of Le Corbusier, for example, in the Maison Citrohan (1920), where the WC is located behind a dwarf wall, and in Maison Ozenfant (1922) and Maison la Roche (1923) the toilets are located in a small niche in the bathroom.

Other contemporary architects also placed the WC directly in the bathroom, but usually this was only done in the large bathroom that was connected to the parents' bedroom. For example, this is the case in "House Sonneveld" (1933), which contains four toilets and three bathrooms [12]. Only in the large bathroom with access from the parents' bedroom, the $\mathrm{WC}$ is a part of the bathroom. Otherwise, there are separate rooms for WCs.

House Sonneveld points to another development, the large master bedroom with direct access to a private bathroom. "The Master Bathroom" was called when it became quite widespread in the US in the second half of 1900s. This was really a significant change compared with the bedrooms one decade earlier, which were fitted with a washstand and a dressing table. Now the bedroom had direct access to a spacious bathroom.

\subsection{Villa Savoye - the Bathroom as the Heart of the} House

Corbusier [13] stressed the importance of hygiene, and in his book "Vers une Architecture" he points out the importance of the bathroom and claims that the bathroom should be seen as a main space in a dwelling. The bathroom should be oriented towards 
south, large areas of glass should ensure plenty of daylight in the bathroom, and direct access from the bathroom to the outside should be established, if possible.

In "Villa Savoye" designed by Le Corbusier in 1928, the personal hygiene was given a special significance. Just inside the entrance door a significant washbasin is located in the middle of the hall (Fig. 3). Other furnishing in the hall are minimized, and thus the washbasin appears very remarkable. Visitors have to wash their hands in the basin before moving along the clinically white walls into the floors above ${ }^{1}$.

Villa Savoye contains three bathrooms and four separate WC rooms. The ground floor contains entrance hall, garage, two rooms for servants, a laundry room and a guest bedroom with a connecting en suite bathroom. There is no bathroom for the servants, but there is a washbasin in each of their rooms and the hall gives access to a small WC room [14]. The first floor, forming the primary part of the dwelling, contains three bedrooms, workroom, kitchen, pantry, living room and a terrace. Inside the larger of the two bedrooms, a bathroom is designed as an open space, sculpturally designed and covered with tiles that create an azure mosaic. The bathroom is located centrally in the house and as a part of the bedroom, it constitutes the second largest room in the house. The bathroom is equipped with a bidet, and the WC is located in a separate space in one end of the bathroom.

The second bedroom also has a private bathroom, however, it is considerably smaller and designed in a separate room next to the bedroom. There is direct access from the bedroom to the bathroom, while the toilet in this case is located in a small room with access from the corridor. The third bedroom has no access to a bathroom, but direct access to a WC room. Nowhere in Villa Savoye are bath and WC located in

\footnotetext{
${ }^{1}$ The washbasin also has a symbolic meaning, concerning a process of mental cleansing: Here the visitor removes residues from the outer world- "the old world". Modernism clinical facades and its clean style was a similar picture in this cleansing process. Humans had to "start afresh" and develop a new civilization.
}

the same room.

The significance of the bathroom and its location in the house varies a lot in the residences of the period. This can partly be explained by different builders' attitude to hygiene and their varying perceptions of the importance of bathrooms, but it also emphasizes the experimental nature of contemporary Modernism. In Le Corbusier's contribution to Weissenhofsiedlung in Stuttgart, one year before he began work on Villa Savoye, there is not the same focus on the bathroom. The dwelling, which is arranged on four floors, contains only one bathroom, while there are three WC rooms, which has been luxury after contemporary conditions. One WC is located on the ground level, the second WC is located in the parents' bathroom on the second floor, and the third WC is located on the third floor near the guest room and the children's room. On the first floor, which contains living room, kitchen and maids room, there is no $\mathrm{WC}$ [12].

\subsection{Bathrooms for the Working Class}

The described dwellings are all designed for a social elite, and it can be pointed out that there are always large bathrooms for the residents in these houses, while the working people (that modernists proclaimed were their target audience) were not allocated a bathroom in the rooms reserved for housekeepers and servants. And likewise, in the housing

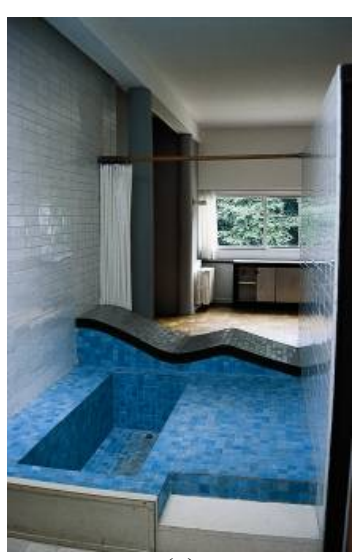

(a)

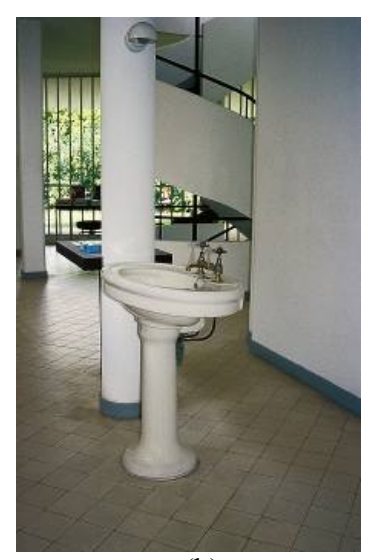

(b)
Fig. 3 Villa Savoye designed in 1928 by Le Corbusier: (a): The bath located in the centre of the villa; (b) The washbasin located in the middle of the entrance hall. 
for the not-so-well-off, the development of bathrooms was not quite as fast. Neither the economy nor the size of these houses left room for large bathrooms and a number of WCs. Here creativity had to be applied in order to integrate hygienic activities in the dwelling, and some of the basic modernist ideals had to be compromised. Adolf Loos, one of the most dedicated proponents of the significance of hygiene, designed for example "Mitzi Schnabel House" (1931-1937), a small single-family house of approximately $80 \mathrm{~m}^{2}$ [11]. In this house, the bathroom (with a sink and a tub) is designed as part of the kitchen - very unlike the idea of the functional zoning of the house. The $\mathrm{WC}$ is in a separate room with access from the dwelling entrance.

In Denmark, the hygienic movement also had a strong influence on the work of architects. The dwelling should be clinically clean, and in line with Le Corbusier, who pointed out how dust could be avoided $^{2}$, it was stated in the Danish Architectural Magazine in 1929 that "curtains should be prohibited in any room as they collect dust and therefore are unhygienic" [15]. It was concluded that any space should be built applying the same principles as those applied to rooms for surgical operations in hospitals.

Housing should be clinically clean, and also personal hygiene should be taken care of. Well-functioning bathrooms were developed in modernist homes designed by architects like Arne Jacobsen, Mogens Lassen and Edvard Heiberg (Fig. 4). The modernist villas, however, had no great popular appeal, and instead two other types of house were developed that embodied the Danish family house, namely "murermesterhuset" (a traditional single-family brick house) and "the bungalow" (Fig. 5).

"Murermesterhuset" was developed in the early 1920s and was typically without bath and WC [16]. In these houses, the bathing function remained in the kitchen and toileting typically took place in a shed in

\footnotetext{
${ }^{2}$ "Never undress in your bedroom", Le Corbusier claimed in one of his books [13].
}



Fig. 4 Bathrooms in the Danish settlement "Blidah Park" (1932-1934). White tiles on the walls and terrazzo on the floor are waterproof and easy to clean. Architect: Edvard Heiberg.

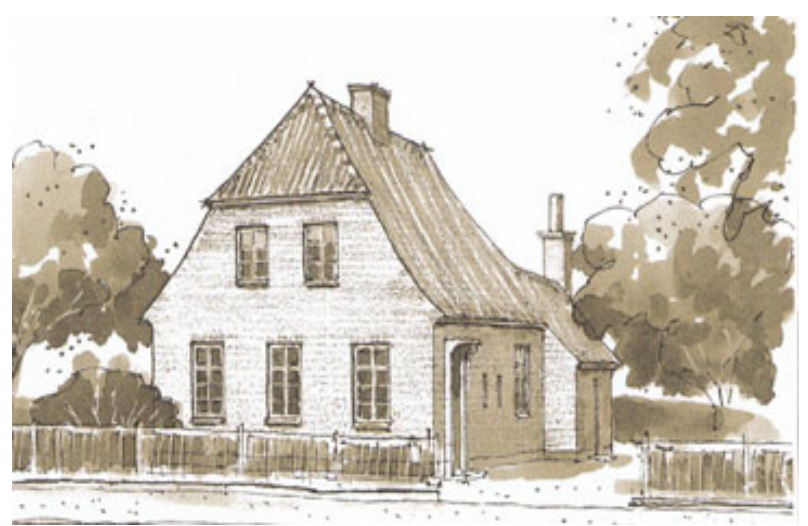

(a)

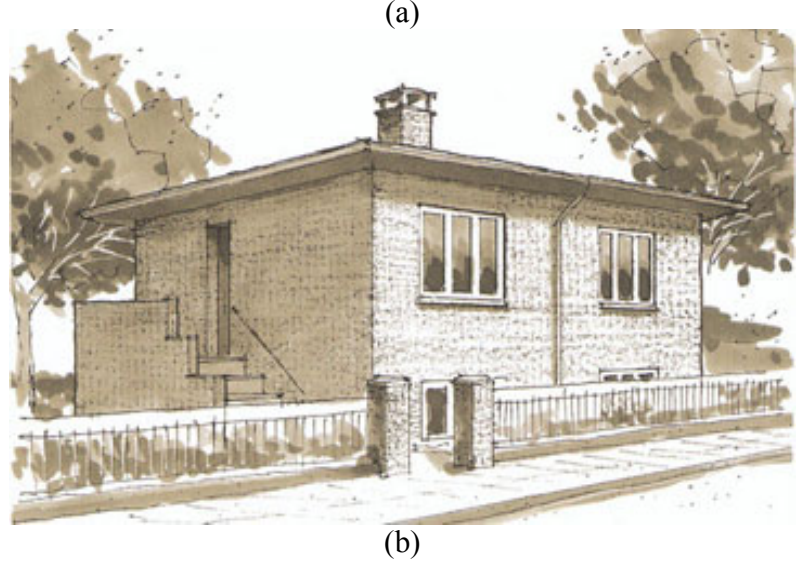

Fig. 5 (a) Typical Danish "murermesterhus" from the 1920s; (b) Typical Danish bungalow from the 1930s. 
the garden. The bungalow was developed in 1930s, when the demands for bathrooms had become more widespread, and several of the bungalows had a bathroom on the ground floor, with a bathtub and a $\mathrm{WC}$ in the same room. But some of the bungalows still had no bathrooms and had a small room with a $\mathrm{WC}$ in the basement.

In multistorey housing blocks bathrooms were also increasingly established, for example in the settlement "Classens Have" from 1925. Here the bathroom, which contains a bathtub and a WC in the same room, was located in a bright room with a large window. The bathroom was accessed from a small corridor between the kitchen and the dining room (Fig. 6), and it was quite common to have small intervening spaces in relation to the bathroom. Similarly in "Solgården" from 1931, the bathroom was located next to a corridor between the kitchen and bedroom. Again, this bathroom was equipped with a bathtub and a WC in the same room, but daylight conditions and ventilation were not as good, as where the bathroom (which was more common in the 1930s multistorey housing) were located in the middle of the apartment.

However, throughout the whole period several housing estates had WCs in the stairways shared by two or more apartments.

\section{1940s and 1950s: Bathrooms in Post War Housing}

\subsection{Hygiene, Infrastructure and Urban Development}

Health and hygiene were still important parameters in housing after World War II. Prominent social physicians diagnosed housing conditions as crucial to a number of serious diseases ${ }^{3}$, and as the welfare state was about to realize its housing programme after the war, it was natural that modernism's housing ideals and planning concepts dominated the development of housing construction.

\footnotetext{
${ }^{3}$ In a doctoral thesis (by Vagn Christensen) from 1956, the poor housing conditions are defined as crucial for the development of tuberculosis and other respiratory diseases.
}

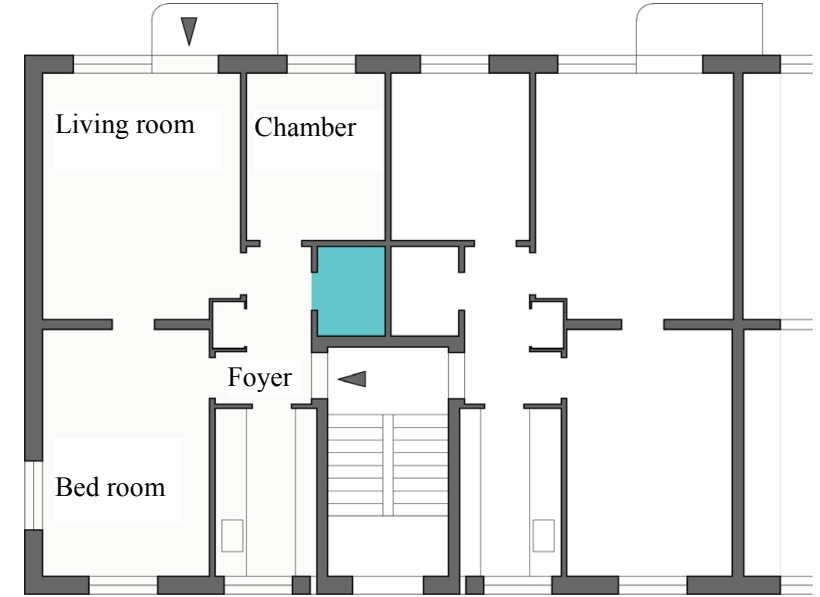

Fig. 6 A typical example of a Danish apartment from the early 1930s, the bathroom is located at the entrance, next to the entrance door.

At the urban level, modernism's ideals of zoning launched as previously described in the Athens Charter in 1933 steered post-war urban development. Cities were divided into residential areas, commercial areas and recreational areas, and between these areas the infrastructure was developed to connect the zones effectively. The infrastructure consisted inter alia of traffic lines of highways and rail links, while the sewers were a secondary and less prominent part of the infrastructure.

Sewerage and sewage discharge was not discussed during this period. It was seen as a perfect and unproblematic solution to the environmental problems that had characterized the cities in the 1800s. Only later, it became apparent that the discharge of sewage into lakes or the sea was not unproblematic after all. Similarly, there was not yet any focus on water consumption in households, even though this was increasing rapidly due to the growing number of installations in households.

The norm was still one daily wash, but the standard of cleanliness increased, and in the US the daily shower, the daily shampoos and the daily use of deodorant became normal [17]. Also in Denmark still more people took care of their personal hygiene in a bathroom equipped with a bathtub (or shower) and with hot water in the tap. While in the beginning of the 20th century only $3 \%$ of Copenhagen housing had 
a bathroom [3], in 1955 this was the case in $36 \%$ of Danish housing (Danish Statistics). In many homes, washstands were thus removed from the bedroom and in still fewer homes the kitchen was used for personal hygiene. Public baths were losing their importance as social meeting places.

\subsection{Bathrooms Become Standard in Housing}

Sewers were hidden away concealed underground, and a social order emerged with a clean and aesthetic coating over an underground chaos of pipelines and sewers. It had its counterpart in the dwellings where the connection to the sewerage system meant that residents could flush the toilet without the effluent being seen or smelled. The bathroom became the place where you got rid of "the dirt" and the perception of the bathroom as rather private was further developed. In the bathroom you could get rid of things that should not be seen in public-everything from matted hair, personal dirt, menstrual pads and medication.

This was particularly evident in the glass houses designed by famous architects in 1950s. Mies van der Rohe's Farnsworth House (Fig. 7) and Philip Johnson's Glass House are the best known. The ideal was to create the transparent house, where spatial relations were in focus, and where the boundaries between interior and exterior and between different functional spaces were fluid. Neither kitchens nor bedrooms were concealed behind closed doors. Nevertheless, the bathrooms are located in a closed core in the middle of the house as the last bastion of privacy. "Out of sight ..." you can say about the bathroom, and it is also underlined by details: In Farnsworth House, all furniture and details were designed by Mies van der Rohe himself-with the exception of the bathroom plumbing.

Both Farnsworth House and Glass House are relatively small dwellings and they were both built as second homes. Second homes meant for leisure are often arranged much more spartan than permanent

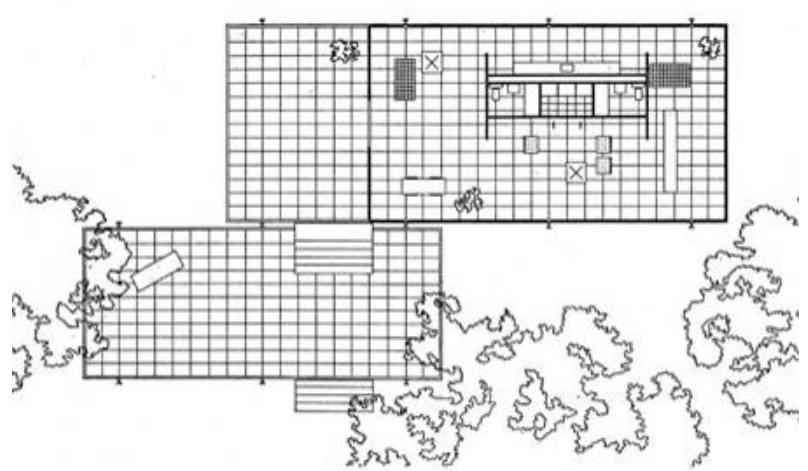

Fig. 7 Mies van der Rohe's Farnsworth House from 1951. The two bathrooms are located in the closed core in the middle of the house.

homes and therefore many people's life in second homes is connected with a more primitive life than everyday life in the permanent house. Still, both houses have well-equipped bathrooms-even two (Farnsworth House), and this emphasizes that the bathroom had become an important part of the dwelling and hard to miss.

The literature often describes bathrooms of the period as small and compared with today's standard it is true. However, the characterization is misleading when compared with the bath conditions of the previous period, that have many examples of large bathrooms, but they are all bathrooms for the affluent part of the population. Housing for the less affluent was more often without any bath at all. The reality is that in the 1950s all new housing was built with bathrooms, also in housing for the population that had previously had no bathroom at all.

\subsection{Bathrooms in Apartments}

The sitdown-bathtub was developed for small bathrooms. It was only about a meter long, and it made it possible to equip a bathroom with a bathtub, even very small bathrooms less than $2 \mathrm{~m}^{2}$. The sit-down-bathtubs were common in small apartments in the $1950 \mathrm{~s}$, for example in the social housing estates. During the 1960s, when a daily bath became increasingly common, showers grew in popularity and in many homes existing bathtubs were equipped with 
shower heads and shower curtains.

All new homes were now equipped with a flushing WC. Thus, the filthy conditions and odours of earlier lavatories were eliminated and it became more obvious to combine the bath and the $\mathrm{WC}$ in one room, which almost always occurred in the Danish apartments of the period (Fig. 8). The combination of a bath and a WC was also developed based on economic and rational considerations, as drainage and water pipes thus could gather. It was particularly important in apartments, where similar considerations resulted in kitchens and bathrooms located side by side. There was one bathroom in each apartment, and usually it was located with access from the hall. The bathroom usually had a window, and there was therefore daylight and opportunities for natural ventilation in the bathroom.

\subsection{Bathrooms in Detached Houses}

In the late 1940s and early 1950s a lot of detached houses were built in Denmark owing to guaranteed government loans. There were several requirements for obtaining the cheap government loans. Government-subsidised houses (statslånhuse-Fig. 9) they were called. They had to be quite small and thus it became an important architectural task to minimize the space everywhere in the house. Another essential requirement was that there should be a bath and a WC in the house. Thus, a number of compact bathroom designs were developed, where space was utilized to the utmost. Again, the sitdown-bathtub was popular. Bathrooms in these houses are typically located in the hall, and thus the situation in the early 20th century, where the lavatory was located in the remotest corner of the dwelling or in a dark basement, was finally abandoned. Now the bathroom including a WC was clean and technically well executed, and it was no longer necessary to hide it away. It was located in the hall, next to the entrance door, and thus easily accessible to guests.

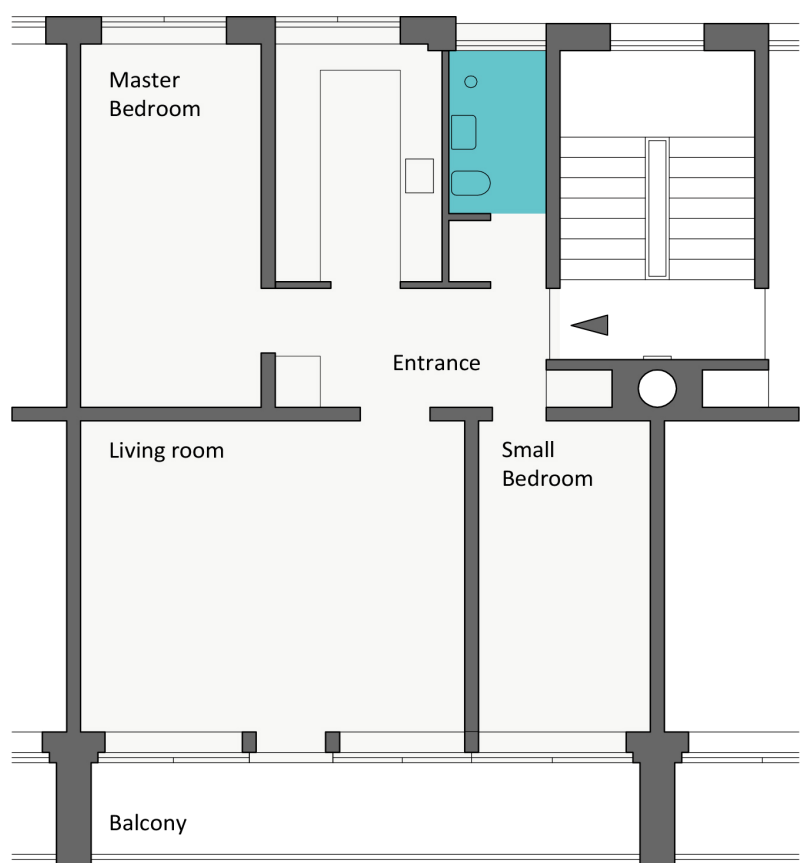

Fig. 8 Copenhagen apartment built in 1949-1951, the size and the location of the bathroom are typical for the period-next to the kitchen with access from the corridor and a window facing north. Architects: Edvard Heiberg and Karl Larsen.



Fig. 9 Danish government-subsidised house, built in 1947. The bathroom is equipped with a small sitdown-bathtub and located in a corridor next to the bedrooms. The bathroom is $4.4 \mathrm{~m}^{2}$ (4\% of the living area). Architect: Sv. O. Roloff-Nielsen. 
In other government-subsidised houses (and other detached houses of the period), the bathroom was located in a more private part of the house, closely connected to the bedrooms. This gave the bathroom a more private touch, but at the same time the bathroom became less accessible to guests. These opposing qualities might have been the reason why larger dwellings began to have a new room, the guest toilet, which became very popular in the 1960s and 1970s.

The bathroom still lived a life in hiding, and when housing plans are examined minutely in the period's literature as well as the organization of individual spaces including the entrance, kitchens etc. are analysed, but the bathrooms are normally omitted in the description. In the period's housing research, bathrooms and WC facilities are also absent. For instance, almost no literature was published on the topic by the Danish Building Research Institute. In the same period, the same research institute published a lot of literature on kitchen design, and it is noteworthy and maybe surprising that the design of bathrooms did not receive the same attention. In view of the period's focus on hygiene and clinical cleanliness, the bath and the WC facilities should have been receiving far greater attention than was the case.

It would have been obvious to subject the activities in the bathroom to the same kind of functional analysis, as that of the kitchen. In the contemporary rational analysis, architects and architectural researchers focused on basic human and universal needs, and what could be more universal and basic than the functions that took place in the bathroom?

The bottom line is that very few reports or other literature dealing with this part of the dwellings were published, and the kind of enthusiasm that Lihotzkys for instance had for the design of kitchens cannot be identified in relation to bathrooms. It seems like bathroom activities were taboo, and it was difficult to write about them or deal with them.

However, in line with kitchen design, also the bathrooms were designed with functionality in mind.
The space was compact and utilized to the utmost, and it was typically fitted with white tiles around the bathtub and with terrazzo on the floors. All surfaces were easy to clean, hygiene was paramount, and pipes were still visible, so they were easy to repair. The interior design of the bathroom differed markedly from the other parts of the dwelling-materials, acoustics and the atmosphere was different.

\section{1960s and 1970s: Bathrooms in Industrial Housing}

\subsection{Prosperity, Construction Boom and Prefab}

During this period prosperity grew dramatically. Industri-alisation of construction was developed and a large amount of new housing was built. In Denmark, 600,000 dwellings were built from 1960 to 1979, and they all had a bath and a WC. The bathroom went from being a luxury to being a general requirement and a natural part of the housing standard. The proportion of dwellings without a bath decreased from $64 \%$ in 1955 to $17 \%$ by the end of 1979 , and the proportion of dwellings without a WC decreased from $38 \%$ to $5 \%$ in the same period.

The significant increase in the number of baths and WCs reveals that it was not only in new buildings that they were installed. In urban renewal projects, baths and WCs were also seen as important housing qualities, and in studies that surveyed the potential need for renewal, the availability of a bath and a WC in each dwelling became important indicators.

The modernist dream of industrializing construction to create a mass production of housing was fully realized in those years, partly through industrial production of detached standard houses, partly in blocks of flats along the crane track. Bathrooms were also mass-produced. In 1967, a prefab bathroom made in plastic was introduced at the World's Fair for Habitat in Montreal [18] and it was subsequently sold and exported in large numbers. The prefabricated bathrooms could be produced in a rational way, and thus associated with economic benefits. Moreover, it 
was stressed that prefab made it easier to ensure quality, as work processes were not disturbed on a busy construction site and were not interfered with by weather problems. Thus, it was easier to reduce the risk of moisture damage ${ }^{4}$.

In Danish, building research of the period, it was the new forms of production and technical building solutions for the assembly of buildings that were in focus when the situation around bathrooms was illuminated ${ }^{5}$. The research in the field of bathrooms was limited and the sparse research still did not focus on the functional design of the bathroom, as had been the case for some decades regarding kitchen design. At the Danish Building Research Institute, the limited studies related to bathrooms focused on prefabrication, and construction, materials and plumbing related to the process of industrialization.

At the beginning of the century, the shower had been regarded as being very luxurious. Now it became increasingly common and in many homes it squeezed out the bathtub from the bathroom. This occurred especially in multistorey housing. This was also the case in a lot of industrial housing of the period, for example the multistorey housing "Høje Gladsaxe" and the low/dense construction "Albertslund Syd", both built in the mid-1960s. In other settlements, however, bathrooms were still equipped with a bathtub.

\subsection{The Private Bathroom and the Guest Toilet}

As prosperity increased, housing requirements increased as well, and dwellings grew in size. In the early 1960s, a Danish standard house averaged $123 \mathrm{~m}^{2}$, while in the late $1970 \mathrm{~s}$ it was $139 \mathrm{~m}^{2}$ [16]. Thus, the bathroom could grow, and bathroom number two sneaked into ordinary homes. The larger of the two bathrooms was typically located in close connection

\footnotetext{
${ }^{4}$ Nevertheless, a lot of the 1970s prefab bathrooms have subsequently been leaking, and in the renovation of the bathroom the prefab system became a problem. It was not possible to repair the units, and therefore the whole bathroom had to be replaced.

${ }^{5}$ This was discovered when I studied the abstracts of Danish research publications of the period.
}

to the bedrooms and it was mainly used by the residents themselves. The other bathroom was often located in the entrance hall, near the living room and easily accessible to guests. The division between "the private bathroom" and "the guest toilet" was common.

The private bathroom was equipped with a bathtub or a shower - or both, which was not uncommon in Danish standard houses of the period. In the private bathroom, the residents could splash with the water and the dirty laundry could be thrown into a basket - this was a private room, not meant for strangers to enter. Here the family members could in turn go, lock the door and be private.

The daily bath was no longer only a matter of personal hygiene. Warm water and comfortable design were standard features of the bathrooms, and many people related the bath with pleasure and well-being. Thus, a developed bath-culture included running water and long showers developed. And as another sign that a growing body worship was about to invade the bathroom, a bathroom scale stood in a corner of the room.

Still ever more features were entering the bathroom [17]. The children played in the bathtub, the husband shaved and the wife did her makeup. A visit to the bathroom could take some time, and in many families congestion could appear in the mornings when several family members would use the bathroom at the same time. This was one of the reasons why more and more houses were built with two bathrooms. In dwellings trying to solve this problem, bathroom number two would be placed in the bedroom corridor, near the larger bathroom. As a guest toilet, however, it was more ideally located in the hall.

A guest toilet was typically arranged in a space of 1-2 $\mathrm{m}^{2}$ (Fig. 10). It was anonymously furnished and equipped with a wash basin and a WC. They reminded you a bit of the WC rooms that were designed in many of modernism villas, where bath and $\mathrm{WC}$, as described, were often separated. In the 1960s and 1970s housing however, there was also a WC in the 


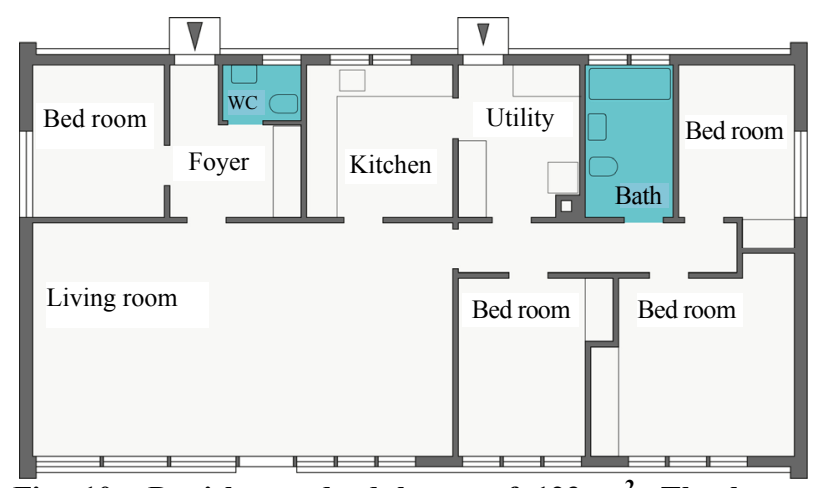

Fig. 10 Danish standard house of $123 \mathrm{~m}^{2}$. The larger bathroom contains a bathtub. The guest toilet is accessed from the entrance hall.

larger bathroom, and this WC was often viewed as more private and was preferred by the residents themselves. A new kind of privacy emerged related to hygiene and cleanliness: You could share a toilet seat with your family while the guests should preferably use another WC.

\subsection{The Bathroom as a Symbol of Lifestyle}

Some houses were built with a sauna, placed near the large bathroom, and in many existing houses saunas were installed in the basement. This can be seen as part of the ideals that emerged in the wake of the youth rebellion in 1968: bodily liberation and nudity enveloped in warmth and framed in untreated wooden boards was like a condensate of the aesthetic ideals of the 1970s.

Saunas are also found in a number of the period's architect-designed houses, and there are no major discrepancies between the location and the decor of the bathroom in these homes compared with the standard housing of the period.

The appearance of saunas can be seen as an expression of the period's prosperity and as a sign of the residents' need to express status and personal lifestyle in their homes. New "styles" of bathroom decor and furnishings were developed. The bright walls and white tiles disappeared and sanitation should no longer be white. Adolf Loos would have turned in his grave if he had seen the brown tile floors, the dark green bathroom tiles and the curry-colored toilet bowls in bathrooms of the 1970s.

In the middle of the period, the energy crisis hit in 1973. Now energy-savings came into focus, and then a bathroom (associated with high energy consumption) was seen with new eyes. The saunas became less popular, and in many homes, they turned into store rooms and were left as a relic from a time when there were abundant resources. Campaigns were launched to get people to conserve hot water, and even the bathtub, which is associated with a high consumption of hot water, became unpopular for a while. While it had been an effort to get people to spend large amounts of water in the beginning of the century (Loos), now reductions of the consumption were in focus.

\section{1980s and 1990s: Environmental Efforts and Postmodern Style}

\subsection{Environmental Problems and Water Savings}

The energy crisis in the 1970s resulted in demands for energy savings in Danish households, other environmental issues were debated for example the aquatic environment. This occurred partly as a result of the sewage from the sewerage network: Previously the waste from the lavatories in the urban courtyards caused extensive environmental and health problems in cities - now the same waste caused environmental problems in the surroundings, lakes and the sea.

Up to now, we had taken care of waste and pollution by moving sources of pollution away from residential areas and by exporting the waste far away. The zoning of cities in business areas, residential areas and recreational areas had actually a fourth zone in the form of the recipients, who served as dumping areas and landfills for waste production in the other three zones.

Sewerage drainage had a collective displacement of the existence of the waste as a result. Now, there was a sudden-but maybe short-awakening when oxygen depletion and dead fishes were discovered in Danish lakes and the sea. Action was needed and 
aquatic environmental legislation was adopted in parliament in 1987, which required that all wastewater should be purified before it was discharged.

Even the consumption and discharge of water from housing came into focus. Water consumption had increased dramatically in the 20th century (Fig. 11), first as a result of increased hygienic requirements and as a consequence of the increased number of bathrooms and WC, next as a result of a lifestyle of consumerism, which could be read on the watermeter. The growing water consumption led to a falling level of groundwater, and this in turn led to lakes drying out as well as streams and other wetlands, which in turn led to the disappearance of habitats of animals and plants. Thus, it was no longer only the hot water that should be used sparingly (as in 1970s) but also the cold water. New campaigns were initiated, partly focusing on behavioral issues (to use water wisely) and partly on water-saving techniques.

\subsection{Ecology and Postmodernism in the Bathrooms}

Thus, long showers were discussed again, more and more Danes learned to turn off the tap when brushing their teeth, and water-saving toilets and other features were developed to reduce water consumption. In experimental housing, rainwater from the roof was collected and used for toilet flushing etc. [18].

Also, the increased focus on discharge of wastewater led to a series of experiments in the period's "ecological housing". Common for all the experiments was a determination to address wastewater locally-directly in residential buildings. In Berlin, several high-profile experiments were thus conducted in this field in the 1980s: In the urban renewal project "Block 103", the wastewater from kitchens and baths was purified in an upright reedbed wastewater treatment system on a gable, and in another urban renewal project, "Block 6" (Fig. 12), also the wastewater from the WCs was purified in a major reedbed wastewater treatment system in the courtyard.

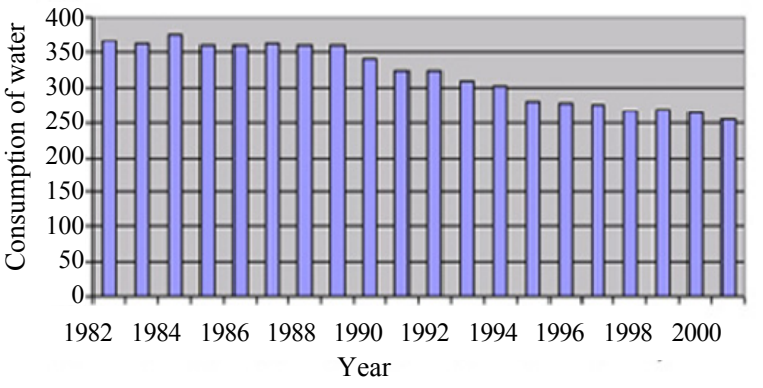

Fig. 11 The consumption of water in Danish households from 1982-2001 (in millions $\mathrm{m}^{3} / \mathrm{year}$ ).

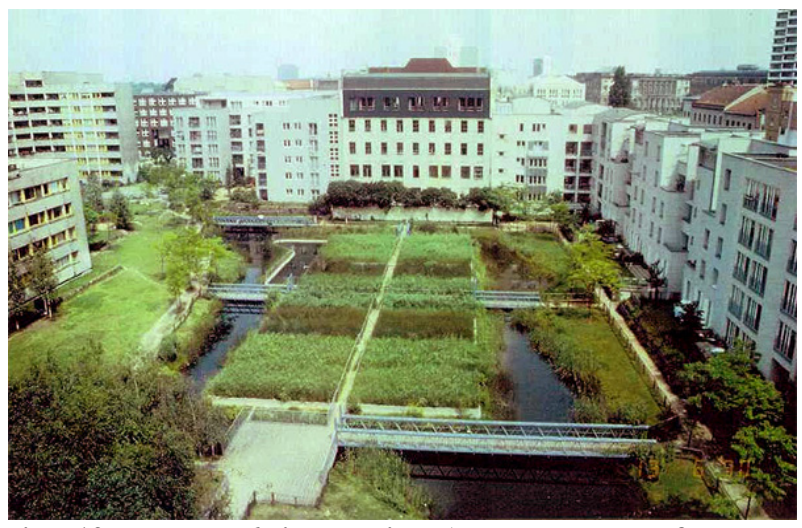

Fig. 12 Block 6 in Berlin. All wastewater from the households is purified in the courtyard of the settlement.

In Denmark, we spoke and wrote a lot about the Berlin experiments in the 1980s, and in the 1990s, similar Danish studies were carried out. In 1991, architect Anne Ørum Nielsen designed Ramshusene, a small housing estate on the island of Bornholm (Fig. 13). Here all wastewater from eight dwellings were purified in a communal shelter, where carps and other fish swam in large pools eating the nutrients in wastewater. When the fish had eaten the residents' waste, residents could eat them.

The flow of resources should be cyclical, and they should be visible. This was an ideal among ecologists, and it was expressed in a large urban renewal project that was implemented in Kolding in 1994. In the middle of a block, a huge greenhouse was built, and in the greenhouse wastewater from the dwellings was used as fertiliser for green plants and other saleable products.

Another way to treat wastewater from dwellings was found in composting toilets, which had been used 


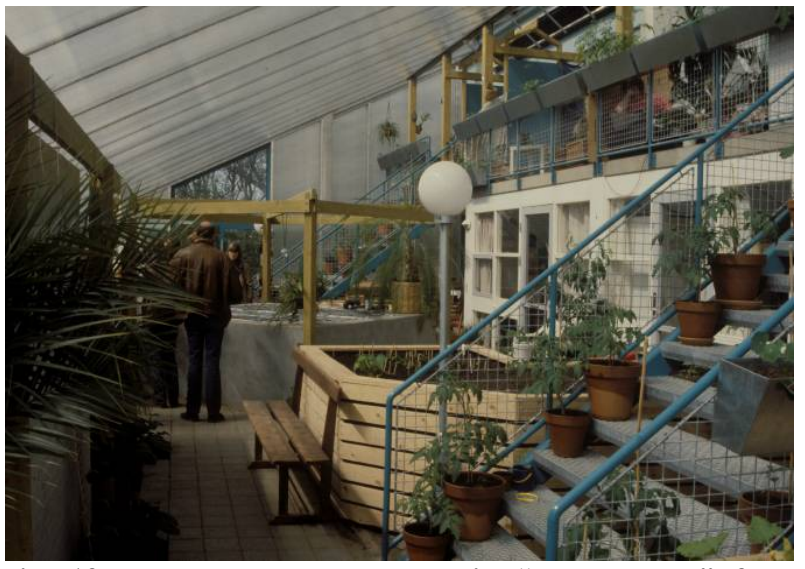

Fig. 13 The communal shelter in "Ramshusene" from 1991. Architect: Anne Oerum Nielsen.

on old Swedish farms for years. In the composting toilet, urine and faeces are collected in separate containers - the urine can be used as fertiliser on fields while faeces decompose and can be spread directly in the private garden. Nevertheless, composting toilets did not have a great impact in a Danish context. Danes had adopted the idea of having wastewater led unseen through appropriate strain, and the visibility of the waste cycles did not appeal to many residents.

The ecological considerations did not affect the location of bathrooms in Danish dwellings, and they did not lead to major changes in bathroom design. In some cases the lavatory bowl changed a bit, but otherwise there were no major changes inside the dwelling. Even the experimental building for a future home, "Villa Vision" built on the outskirts of Copenhagen in 1995 was fitted with a very traditional bathroom.

\subsection{Postmodernism}

Ecological housing had its counterpoint in a more decadent version of the postmodern lifestyle. In the movies, this trend was introduced by Jean-Jacques Beineix in the movie Diva from 1981. In this scenery, traditional arts and elitist elegance are woven together with pop culture and minimalism. Thus, the movie is full of surprising juxtapositions - also in its view of the bathroom: The main character is living in a loft in a raw warehouse with a classic bathtub standing in a corner of the large room. The main character sits in it, smoking a big cigar, while a young woman moves around him on rollerskates.

Jean-Jacques Beineix' bathtub was very present in the movie, a sign that the bath was increasingly becoming linked to lifestyle and wellness. Whereas earlier the focus on bathrooms was mainly on technical and hygienic conditions, now bathrooms were increasingly seen as a matter of design and personal expression [8]. Bathrooms became trendy and the subject of design.

The most famous example is perhaps Phillip Starck's design of Cafe Costes in Paris in 1984. Starck's design is not confined to the bar or to the café's famous furniture. The design included urinals and sinks in the café toilets.

The post-modern architecture came to Denmark in a subdued and processed form. It happened for example in the settlement "Dalgas Have", designed by Henning Larsen Architects in 1989-1991 (Fig. 14). The settlement arranged with a symmetrical plan composed of geometric forms, and it gives an expression of the ideals of the period: Housing should appear magnificent to the outside.

The pompous expression on the housing façades often had a price to be paid in the housing interior, which also can be experienced in the bathrooms in Dalgas Have. Either the bathrooms are located in the

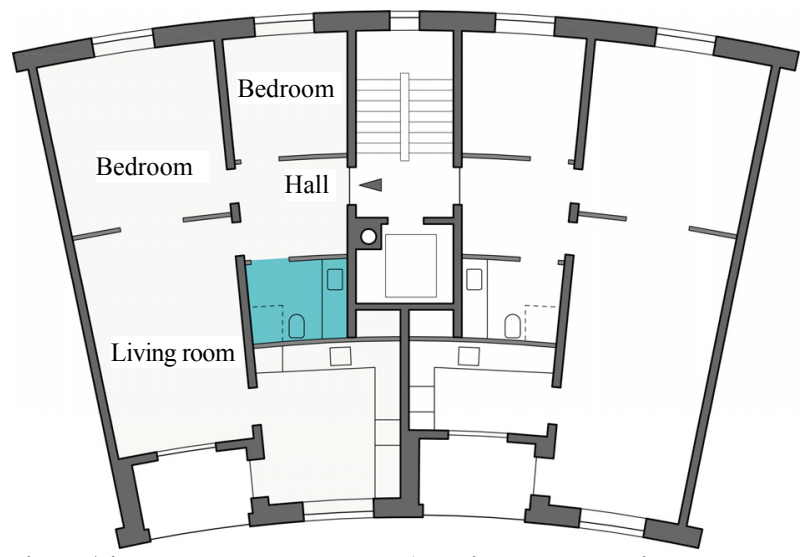

Fig. 14 Dalgas Have, Architect: Henning Larsen Architects. 
middle of the building without windows to the outside - or they have very small windows facing an opposite facade.

The bathroom design should also look rich and pompous. Large mirror arrangements with built-in spotlights were developed, traditional WCs with an exposed cistern was increasingly replaced by wall-mounted WCs with cisterns and piping that were concealed. The built-in cistern was often quite bulky as there was usually built a desk across the room's width, for incorporation of the relatively small cistern, but it was worth the price: the bathroom should not appear as a space that was constructed exclusively from functional considerations. The bathroom should be a stylish space in which a stay was a pleasure.

It became increasingly obvious that the bathroom was becoming a part of the creation of "home feeling", which became so important in these years [19, 20]. Bathrooms developed (in line with kitchens and living rooms) into rooms where good taste and personal style were demonstrated [7]. Washbasins had hitherto been produced over the same template with a few variations, by now they were designed in all sorts of shapes, and new types of lighting and tiles were produced. The bathroom was developed as a marker of personal identity.

At the same time, the dwelling became increasingly important for many residents as a refuge [17]. They experienced daily life as busy and hectic, and they saw the dwelling as a "home" where they could retire in peace. This trend had a special significance for the bathroom in the late 1990s, when luxurious Jacuzzis and spas were targets for many homeowners, as the housing market was soaring with resulting economic opportunity.

With plenty of hot water bubbling in the tub, it was no longer the environment that was prioritised. With the required chlorine and other chemicals in the water, it was probably also not the physical health and hygiene that were prioritised. It was rather the residents desire to relax and regain an inner peace and balance that was the driving force. In the beginning of the 20th century, the bathroom was developed with physical health in mind. At the end of the 20th century, the bathroom design was focusing on mental health.

\section{Today: Bathrooms in the New Millinium}

\subsection{New Trends}

Residential construction over the past 10 years has been divided into two periods. The period up to 2007 was marked by economic growth, and in most countries many new dwellings were built. It was also the case in Denmark. As the economic crisis hit in $2007 / 2008$, new construction stopped. It is too early to determine what impact the new economic situation can have on bathroom design, but since the bathroom has been the venue for major investments over the last decade where lifestyle, wellness and luxury have been important ingredients, it is expected that the economic slowdown will lead to new trends.

Moreover, in the last decade, climate changes have given a new focus on consumption in Danish households. As a large proportion of energy and water consumptions in the households are used in the bathroom, a new attitude to the bathroom may emerge. Will spas and Jacuzzis come to idle, just as saunas became less interesting and faded into the background in the wake of the energy crisis in 1973 ?

One can point out a number of trends that seem to be the hallmark of today's bathrooms. These are trends that work in parallel and simultaneously, but in many ways contradictorily.

\subsection{Privacy and the Erosion of Spatial Boundaries}

The privacy that started as a moral code demanding bath and toileting to be done in secret has been developed and have become very visible in the spatial organisation of housing. For example the "master bathrooms", which were introduced in several modernist houses in the 1930s, have become increasingly common in Danish standard houses. Designed for the parents the master bedroom in these 
houses often has direct access to a bathroom that is well hidden from other functions in the dwelling. The bathroom is only accessible to parents and the bathroom has become parents' sacred place-the finest domain of privacy.

Today the significance of homes as a private domain is under pressure. Homework, internet, mobile phones etc. are all pushing the boundaries of privacy around the dwelling. In this context one quality of the bathroom becomes evident: Here, residents can lock the door and be themselves without being questioned [8].

The privacy associated with the bathroom has thus been developed for a special quality of this space [8]. This is exploited in various ways in modern interior design, where the bathroom's traditional features are complemented with other features, such as a workstation or a small library (Fig. 15). The idea is that the bathroom is the last place where you can lock the door and be on your own.

Other housing projects are the exact opposite. Ever since modernism was introduced in the early 20th century, it has been an architectural ambition to create dynamic spaces and to remove architectural boundaries - between the interior and the exterior, between kitchen and living room, between dwelling floors, etc.. This was the case for example in Farnworth house and Glass House (Fig. 7), where the bathrooms were the last spaces that could be closed with a door.

Now the turn has also come to the bathroom. As was the case in the movie Diva, the bathtubs and spas become part of bedrooms and living rooms. This happens for example in a housing project "Slender" designed in Berlin by the German studio, Deadline Architects (Fig. 16). A family apartment is arranged on the two upper floors where the parents' bedroom is located on a ramp in a double high living room and a bathtub is located at the beginning of the ramp-in open space. Besides the bathtub, a WC and a wash basin are located behind a sliding door with frosted glass.
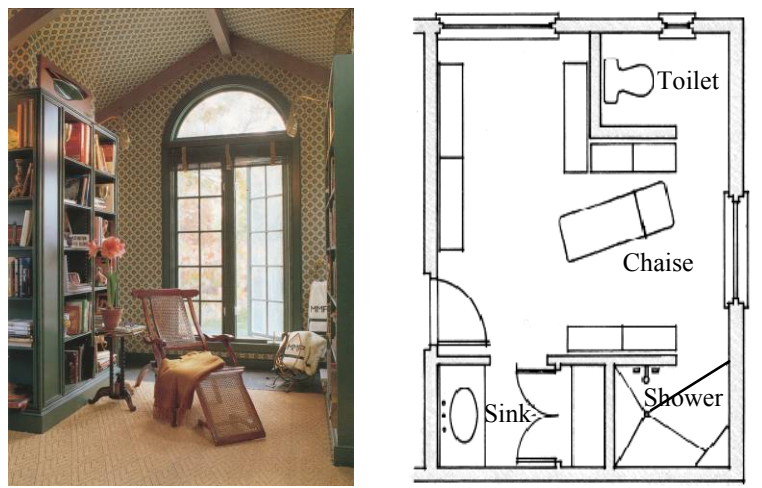

Fig. 15 The privacy associated with bathrooms is developed in new designs. In this apartment, a study is designed in the bathroom. The resident wanted a private study, and this was combined with the privacy of the bathroom.
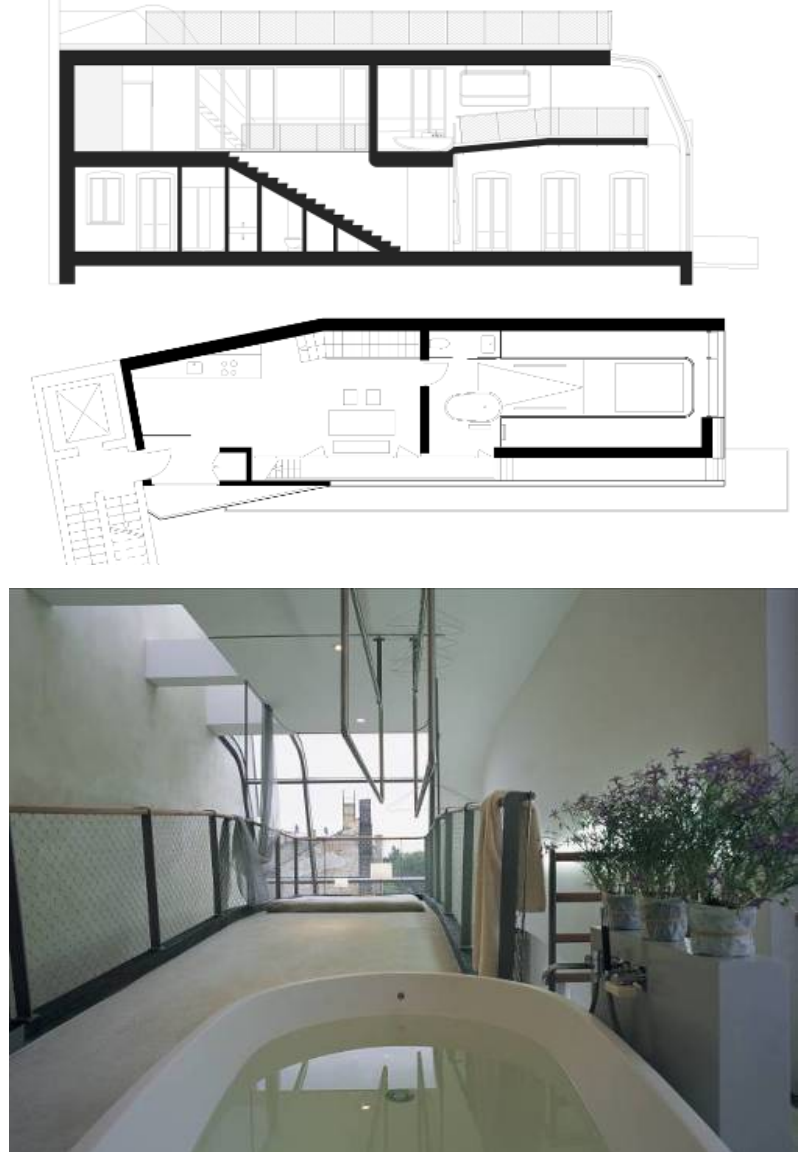

Fig. 16 The bathtub in open space in "Slender" in Berlin. Architects: Deadline Architects.

\subsection{Physical Hygiene and Mental Cleaning}

As described in this article, health sciences and the hygienic movement had great importance for the development of bathrooms, as we know them today. 
The development began in early modernism, where the bathroom was functionally furnished with tiles and other easy-to-clean materials. The bathroom was developed with the aim of creating physical cleanliness.

Personal hygiene is still in focus. The standard is still a daily bath and cleansing of dirt has been further enhanced. It happens in the physical space where detergents and anti-bactirological liquids are used in an effort to obtain the illusion of a clinically clean room, and it happens on a personal level, where the daily bath and personal hygiene has been expanded to include pealing, detox etc..

However, nowadays physical cleansing has its counterpart in a mental cleansing, which also takes place in bathrooms. The bathroom has developed into a retreat where residents can relax and forget the daily stress. $40 \%$ of American women find that their main means of relaxation is taking a bath [8], and new facilities such as spas and Jacuzzis have precisely this feature in mind. It is about finding peace in a state of physical and mental well-being.

The bathroom seems to be well suited to create this mental well-being - inter alia due to the privacy associated with the bathroom. The bathroom opens up an intimate world where you can forget the outside world.

\subsection{Bathrooms as a Personal Show Room}

In recent years, the (unilateral) functional approach to the design of bathrooms has declined, and increasingly there has been focus on the bathroom "style" [8]. The bathroom has become a design object. This shift from focusing mainly on technical and functional features of bathrooms to focusing on the bathroom design as an aesthetical matter is a natural extension of the postmodern ideals. At the same time they can be viewed as part of the resident's effort to create a "home" in accordance with their personal taste. Like with kitchen design bathrooms have evolved into an important venue for residents' self-realisation and for their reflection of personal identity. In this context the design, the details and the materials of bathrooms are probably as important as the practical function of the bathroom. Bathroom aesthetics increased in importance.

In recent years, the (unilateral) functional approach to the design of bathrooms has declined, and there has increasingly been focus on the bathroom "style" [8]. The bathroom has become a design object. This shift from focusing mainly on the technical and functional features of bathrooms to focusing on bathroom design as an aesthetical matter is a natural extension of the postmodern ideals. At the same time it can be viewed as part of the residents' effort to create a "home" in accordance with their personal taste.

\section{Conclusions}

This article has focused on varying trends in the view and the design of 'space for personal hygiene. The trends have been described on many levels, and they are not all pointing in the same direction. In this conclusion I will focus on four major trends that can be summarised as follows:

Throughout the 20th century the standards of personal hygiene have become higher. This has been expressed in the bathrooms in Danish housing. The number of bathrooms in each dwelling has increased, and the size of each bathroom has grown. Also, a lot of economic resources have been invested in renewal of decorating bathrooms in existing housing.

In the beginning of the 20th century focus was on "a healthy mind in a healthy body". Nevertheless, in contemporary housing architecture the physical health and physical hygiene was the primary task. In the bathroom design of the last two decades, the focus on the mental health has been ever more important. Thus in bathroom design including Jacuzzis and spas, the bathroom is developed into a retreat where residents can forget the daily stress - in silence and privacy.

This privacy is a new quality of bathrooms. In the beginning of the 20th century, many residents took 
their weekly bath in a public bath and the latrines were located in the semi-public courtyard. Today the bathroom including WC has developed into the most private room in the dwelling. This is exploited in new housing, where traditional bathroom features are complemented with other features, such as a workstation or a small library. The bathroom might be the last space where you can be on your own.

In the beginning of the 20th century, the WC room was seen as "the necessary" and like the bathroom it was hidden far away from the representative spaces. As is the case with kitchen design, today's bathrooms including WCs have evolved into an important space for residents' self-realisation and for their reflection of personal identity. In this context the aesthetical design of bathroom has increased in importance.

Nevertheless, many trends concerning today's bathrooms are contradictory. Still they exist side by side - not only in the sense that neighbours may have different lifestyles and different preferences of bathroom design. Also in the sense, different trends can coexist within the one and same family. In the morning you may need a bathroom for a quick shower, and later the very same day you may need a retreat in hot bubbling water. The bathroom of today satisfies both needs.

\section{References}

[1] C. Bech-Danielsen, The kitchen: An architectural mirror of everyday life and societal development, Journal of Civil Engineering and Architecture 6 (2012) 457-469.

[2] C. Bech-Danielsen, Modern Architecture-What's the
Matter?, Systime Publicher, Aarhus, 2004. (in Swedish)

[3] B. Vorre, The 20th Century House, Nyt Nordisk Forlag, Copenhagen, 2008. (in Swedish)

[4] K. Lützen, The City Tamed, Hans Reitzels Publisher, Copenhagen, 1998.

[5] J. Hudson, Restroom, Laurence King Publishing Ltd., London, 2008.

[6] J. Burnett, Social History of Housing: 1815-1970, The University Press, Cambridge, 1978.

[7] J.M. Snow, Bathroom Design, National Association of Home Builders, Washington, 1987.

[8] C.C. Madden, Bathrooms, Clarkson Potter/Publishers, New York, 1996.

[9] J. Wissinger, Victorian Details, E.P.Dutton, New York, 1990.

[10] D. Sudjic, Home: The Twentieth-Century House, Festival Company Ltd., Glasgow, 1999.

[11] R. Bock, Adolf Loos: Works and Projects, Skira Editore, Milano, 2007.

[12] F.R.S. Yorke, The Modern House, The Architectural Press, London, 1948.

[13] L. Corbusier, Towards a New Architecture, Architectural Press, Oxford, 1989.

[14] W.G. Boesiger, H. le Corbusier, 1910-65, Praeger, New York, 1967.

[15] K.V. Barfoed, The Design of Gyms in Modern Schools, Arkitekten, Denmark, 1929, pp. 57-59. (in Danish)

[16] O. Lind, J. Møller, Behind the Hedge, Achitectural Press, Copenhagen, 1996. (in Danish)

[17] T. Cowan, Beyond the Bath, Running Press Book Publishers, Pennsylvania, 1983.

[18] M. Gilliatt, Bathrooms: A Study Book, The Viking Press, New York, 1971.

[19] K. Gram-Hanssen, C. Bech-Danielsen, House, home and identity from a consumption perspective, Housing, Theory and Society 21 (1) (2004) 17-26.

[20] M. Gullestad, Culture and Everyday Life, Tracking the Modern Norway, University Press, Oslo, 1989. (in Danish) 